EXTENDED REPORT

\title{
The effect of simulated obstructive apnoea on intraocular pressure and pulsatile ocular blood flow in healthy young adults
}

\author{
P O Lundmark, G E Trope, J G Flanagan
}

Br J Ophthalmol 2003;87:1363-1369

See end of article for authors' affiliations

Correspondence to: Professor John G Flanagan, Department of Ophthalmology, and Vision Sciences, TorontoWestern Hospital East Wing 6-503 399, Bathurst Street, Toronto, ON M5T 2S8, Canada; igflanag@uwaterloo.ca

Accepted for publication 3 March 2003

\begin{abstract}
Aim: To investigate the effect of negative inspiratory effort, as generated by the Mueller manoeuvre, on intraocular pressure (IOP) and pulsatile ocular blood flow (POBF) in healthy young adults.

Methods: Seven volunteers with no history of systemic or ocular disease were recruited (mean age 30.7 years, range 25-40 years, M/F: 4/3). After initial instruction and practice of the Mueller manoeuvre, baseline measurements of IOP and POBF were obtained for both eyes after 10 and 15 minutes of rest, respectively, in the supine position. Thereafter, the Mueller manoeuvre was performed creating a mouthpiece pressure of $-20 \mathrm{~cm} \mathrm{H} O$, for at least 15 seconds followed by a 5 minute rest. The manoeuvre was repeated with a mouthpiece pressure of $-40 \mathrm{~cm} \mathrm{H}_{2} \mathrm{O}$. IOP and POBF were measured 5-15 seconds into the manoeuvre for both $-20 \mathrm{~cm} \mathrm{H}_{2} \mathrm{O}(\mathrm{M} 2 \mathrm{~A})$ and $-40 \mathrm{~cm} \mathrm{H} \mathrm{H}_{2} \mathrm{O}$ (M4A) and directly upon recovery (after two respiratory cycles) from each manoeuvre (M2B, M4B). Baseline measurements were compared using paired $t$ test, whereas manoeuvre induced changes in IOP and POBF were analysed individually using repeated measures ANOVA with Student-Newman Keuls post hoc analyses. Linear regression analysis was used to investigate a dose-response effect.

Results: No significant differences were found between baseline measurements so they were subsequently pooled. There was a significant decrease in IOP for $M 2 B(-9.2 \%, p<0.05), M 4 A(-13.8 \%, p<0.05)$, and $M 4 B(-15.6 \%, p<0.05)$, relative to baseline. A dose-response relation was found for the effect of mouthpiece pressure on measurements 5-10 seconds into the manoeuvre (M2A and M4A, $r=0.54$, $p=0.045$ ). There was a trend of increased POBF relative to baseline for all measurements; however, significance was reached for $M 4 B$ only $(p=0.039)$.

Conclusion: It was shown that forced inspiratory efforts as generated by the Mueller manoeuvre are associated with a dose dependent decrease in IOP and a concomitant increase in pulsatile ocular blood flow.
\end{abstract}

$\mathrm{R}$ espiratory fluctuations in the intraocular pressure (IOP) are a well known phenomenon that is caused by blood pressure (BP) related volume changes in the vascular beds of the eye. ${ }^{1}$ During spontaneous breathing there is a sinusoidal variation in blood pressure that can be attributed to the mechanical effect of pleural pressure swings on the venous return to the heart. ${ }^{2}$ However, during greater respiratory efforts, such as deep breathing and forced inspiratory or expiratory manoeuvres, the $\mathrm{BP}$ response is also influenced by several autonomic cardiovascular reflexes such as cardiopulmonary reflexes, pulmonary reflexes, and arterial reflexes. ${ }^{3}$

Obstructive sleep apnoea (OSA) is a complex disorder characterised by upper airway collapses during sleep and by the persistence of inspiratory effort during the interruptions of airflow. ${ }^{45}$ Whereas the term apnoea refers to total obstruction of airflow, the clinical definition of OSA includes both total and partial airway obstructions (hypopnoea) lasting for 10 seconds or more. Polysomnographic evidence for OSA ( $\geqslant 10$ episodes $/ \mathrm{h}$ ) has been found in $15 \%$ of men and $5 \%$ of women between the ages of 30 and 60 years. ${ }^{6}$

OSA is associated acutely with repetitive negative intrathoracic pressure from inspiratory efforts. The inspiratory effort when breathing is resumed, in combination with hypoxaemia, acidosis, and arousals results in dramatic fluctuations in the haemodynamics of the cardiovascular system and in the haemodynamics and fluid dynamics of the cerebrovascular system. ${ }^{7-13}$ These nocturnal fluctuations are believed to contribute to the increased cardiovascular and cerebrovascular risks reported in subjects with OSA. ${ }^{14-20}$
Recent research has indicated that OSA may have neuroophthalmological consequences. Mojon and coworkers ${ }^{21}$ found a high prevalence of primary open angle glaucoma among patients with sleep apnoea, and Hayreh ${ }^{22}$ described a high prevalence of sleep apnoea among patients with anterior ischaemic optic neuropathy. Other neuro-ocular manifestations reported in case series/reports have included visual field defects $^{23}$ and swelling of the optic disc. ${ }^{24} 25$

Despite the suggested risk of OSA on ocular structures, little is known about the immediate consequences of inspiratory efforts on IOP and ocular haemodynamics. Therefore, in this study we investigated the acute effect of negative intrathoracic pressure, as generated by forced inspiratory effort (Mueller manoeuvre), on IOP and pulsatile ocular blood flow (POBF) in healthy young adults.

\section{METHODS}

\section{Subjects}

Seven young volunteers were recruited for the study (mean age 30.7 years, range $25-40$ years, female:male ratio $4: 3$ ). The research followed the tenets of the Helsinki agreement, had institutional approval, and all subjects were volunteers who granted informed consent. Self reported health was good for all subjects, and there was no history of systemic or ocular disease.

\section{Measurements}

Intraocular pressure and POBF were obtained using a handheld ocular blood flow pneumatic tonograph (OBF Laboratories UK Ltd, software version 11.1) with the subject 
in a supine position and after instillation of a topical anaesthetic (one drop of oxybuprocaine (proparacaine) $\mathrm{HCl}$, $0.5 \%$, Dioptic Lab). The OBF tonograph works on the pressure-volume relation described by Langham et al, ${ }^{26-28}$ where the amplitude and the shape of the IOP pulse together with the heart rate form the basis for calculation of the pulsatile component of ocular blood flow. As the major part of the total ocular circulation is accounted for by the choroid, ${ }^{29}$ it is thought that POBF reflects the pulsatile component of the total ocular blood flow. ${ }^{26}$ Although the exact proportion of the total blood flow that is pulsatile is currently unknown, estimates indicate it to be between $50 \%$ and $80 \%{ }^{26}{ }^{30}$

The OBF instrument samples IOP at $200 \mathrm{~Hz}$ over a time interval of 5-20 seconds using a sterile disposable probe. A built-in processor analyses different characteristics of the IOP pulse waves and selects the five most representative pulses for the calculation of $\operatorname{POBF}(\mu \mathrm{l} / \mathrm{min})$. Other output parameters include IOP (mean, maximum, minimum), pulse amplitude, pulse volume, and a number of flow related measures. In this study, only average IOP and POBF were included in the analyses. Measurements obtained with the OBF tonograph have been reported to have acceptable accuracy and reproducibility. ${ }^{31-35}$

Forced inspiratory efforts were generated by performed Mueller manoeuvres. A Mueller manoeuvre represents the opposite of a Valsalva manoeuvre by forced inspiration against occluded upper airways. The Mueller manoeuvre is associated with a reduction in arterial blood pressure, stroke volume, and cardiac output caused by several mechanisms with different time constants. ${ }^{36}{ }^{37}$ Several studies have used the Mueller manoeuvre to simulate the acute haemodynamic effects of negative intrathoracic pressure during obstructive sleep apnoea. ${ }^{38-40}$

To control the Mueller manoeuvre, the subject breathed through a mouthpiece with a ventilatory hole that could be blocked with one finger at the end of expiration. The mouthpiece was connected to a manometer and a pressure transducer via a system of tubing (Fig l), and the signal from the pressure transducer was amplified (Validyne) and sampled at $100 \mathrm{~Hz}$ by a multichannel acquisition software (Windaq/100, Dataq Instruments, OH, USA). Mouth pressure changes have been shown to closely reflect changes in the intra-alveolar pressure. ${ }^{41}$ Before measurements the system was calibrated against a water column. To ensure that the inspiratory effort was maintained at a constant level during the manoeuvre a custom made audiofeedback system was used where the subject matched two audible tones by adjusting the mouthpiece pressure (Fig 1).

Brachial blood pressure (BP) was recorded from the subject's right arm in the supine position and after 5 minutes, rest using an automatic oscillometric blood pressure monitor (Lifestat 200, Physio-Control, Redmond, WA, USA). Average values were calculated from three recordings, separated by 1 minute intervals.
In addition to brachial BP, beat to beat finger arterial BP was measured from index or middle finger of the left hand using the Finapres 2300 device (Ohmeda, Madison, WI, USA). Analogue outputs of blood pressure and heart beat were recorded at $100 \mathrm{~Hz}$, in parallel with the mouthpiece pressure. Finger arterial BP was not included in the final analysis.

\section{Protocol}

After initial instruction and a satisfactory practice of the Mueller manoeuvre, baseline measurements of IOP and POBF were obtained from one eye after 10 minutes' and 15 minutes' rest in the supine position (Fig 2). Thereafter the Mueller manoeuvre was performed at the end of a normal expiration, creating a mouthpiece pressure of approximately $-20 \mathrm{~cm} \mathrm{H}_{2} \mathrm{O}$ for at least 15 seconds, followed by 5 minutes of rest. The Mueller manoeuvre was then repeated creating a mouthpiece pressure of $-40 \mathrm{~cm} \mathrm{H}_{2} \mathrm{O}$ for at least 15 seconds. We chose these two levels of inspiratory effort based on reported measurements of oesophageal pressure in subjects with sleep apnoea where the inspiratory effort has been shown to vary between $-19 \mathrm{~cm} \mathrm{H}_{2} \mathrm{O}$ and $-48 \mathrm{~cm} \mathrm{H}_{2} \mathrm{O}$ depending on age and sleep stage. ${ }^{42}$ The mouthpiece was not provided with an air leak; however, subjects were asked to avoid using cheeks or the tongue to maintain the negative pressure during the manoeuvre.

Measurements of IOP and POBF were obtained 510 seconds into the manoeuvre for both $-20 \mathrm{~cm} \mathrm{H}_{2} \mathrm{O}$ (M2A) and $-40 \mathrm{~cm} \mathrm{H}_{2} \mathrm{O}$ (M4A) and directly upon recovery from each manoeuvre-that is, within two respiratory cycles (M2B and M4B). These measurements were performed directly after the manoeuvre to investigate the effects of simulated apnoea termination when profound increases in systemic blood pressure and intracranial pressure are known to occur. ${ }^{710134344}$

OP/POBF measurements

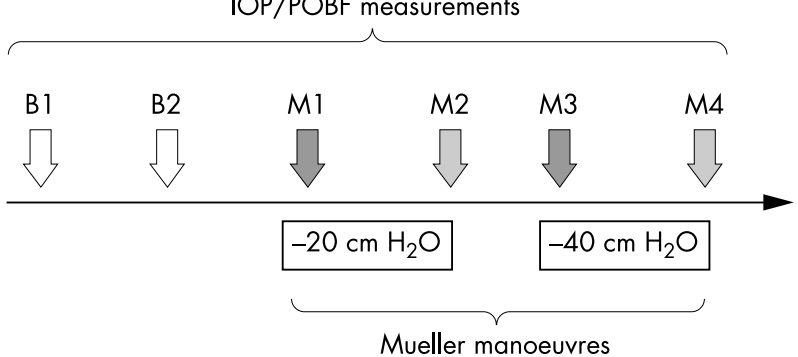

Figure 2 An outline of intervention and measurements included in the study. Scales are not proportional. Each Mueller manoeuvre was at least 15 seconds. The two Mueller manoeuvres were separated by 5 minutes' recovery. IOP/POBF measurements are marked with arrows. B1 and B2. Baseline measures performed after 10 and 15 minutes of rest respectively. M1 and M3. IOP/POBF measurements performed 5-10 seconds into the Mueller manoeuvre. M2 and M4. IOP/POBF measurements performed 1-2 respiratory cycles after completed Mueller manoeuvre.
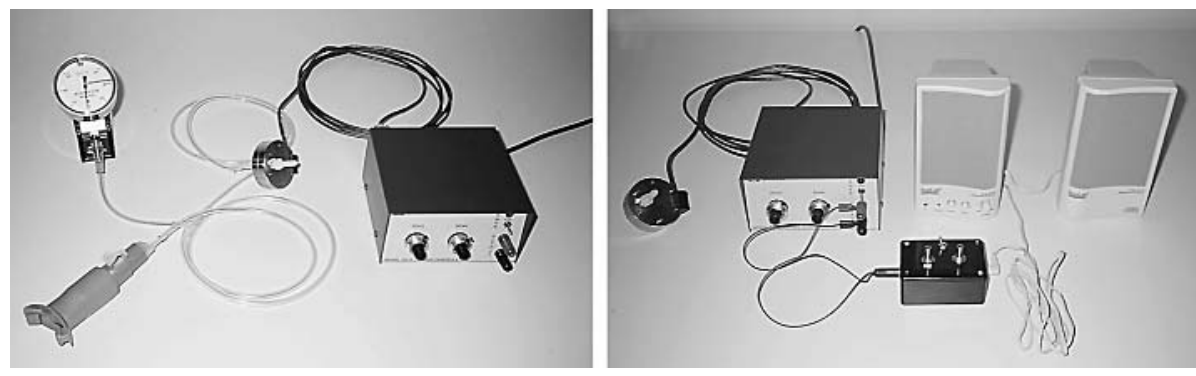

Figure 1 (Left) Equipment used for the Mueller manoeuvre: mouthpiece, manometer, pressure transducer, and amplifier (Validyne). Output was calibrated against a water column. (Right) Audiofeedback system built to help the subject keep a constant inspiratory effort during the Mueller manoeuvre. 


\section{Statistical analyses}

Baseline measurements were compared on an individual basis, using paired $t$ tests. The effects of the Mueller manoeuvres on IOP and POBF were analysed as changes relative to baseline, using repeated measure analysis of variance (ANOVA) and Student-Newman Keul tests for pairwise comparisons. These analyses were performed individually and for the group as a whole. Associations between respiratory effort and change in IOP and POBF were tested for by linear regression analyses. Spread of data is expressed in standard deviation (SD) for individuals and in standard error of the mean (SEM) for the group of subjects. Statistical significance was set at $\mathrm{p}<0.05$ (two tailed test). All statistical analyses were conducted using the SAS (8.2) statistical package.

\section{RESULTS}

A sample from one subject of the recorded mouthpiece pressure, beat to beat finger arterial $\mathrm{BP}$, and pulse rate during a Mueller manoeuvre of $-40 \mathrm{~cm} \mathrm{H}_{2} \mathrm{O}$ is shown in Figure 3.

At the beginning of the manoeuvre there was a parallel decline in BP and pulse rate. For the shortest manoeuvresthat is, around 15 seconds, this decline would last the whole manoeuvre, or almost the whole manoeuvre. In subjects with manoeuvres longer than 15 seconds, pulse rate started to increase before the end of the manoeuvre. Immediately after a completed manoeuvre there was a marked increase in both $\mathrm{BP}$ and pulse rate, followed by a gradual decline to premanoeuvre levels.

Demographics of the subjects are presented in Table 1 . There were no statistical differences between baseline measurements of the IOP and POBF. As a result, measurements at $\mathrm{B} 1$ and $\mathrm{B} 2$ were pooled and an average baseline value was used for comparison with measurements during the two Mueller manoeuvres.

Results from the two Mueller manoeuvres are shown in Tables 2 and 3, and average results for all individual mean outcomes $(n=7)$ are illustrated in Figures 4 and 5 .

Negative mouthpiece pressure was associated with a lowering in IOP (Table 2). This effect was most marked for the greater negative pressure $\left(-40 \mathrm{~cm} \mathrm{H}_{2} \mathrm{O}\right)$ where the decrease in IOP varied between $-4.3 \%$ and $-33.0 \%$ and reached significance for all subjects and the group as a whole. The lesser negative pressure manoeuvre $\left(-20 \mathrm{~cm} \mathrm{H}_{2} \mathrm{O}\right)$ was associated with smaller magnitudes of change of IOP and with greater interindividual variability of the direction of the early responses in particular. Whereas average decrease in IOP for the whole group reached significance both during and after the Mueller manoeuvre at $-40 \mathrm{~cm} \mathrm{H}_{2} \mathrm{O}$ (M4A: $-13.8 \%$, M4B: $-15.6 \%, p=0.004)$, only the period after the manoeuvre produced a significant lowering of IOP at $-20 \mathrm{~cm}$ $\mathrm{H}_{2} \mathrm{O}$ (M2B: $\left.-9.2 \%, \mathrm{p}=0.013\right)$. Consequently, IOP measurements taken directly after the manoeuvres (M2B) were significantly $(p \leqslant 0.05)$ lower than those obtained during the

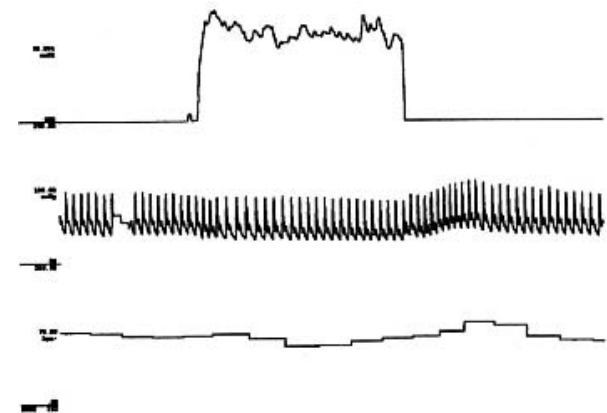

Figure 3 A representative 60 second sample of mouthpiece pressure (top), beat to beat finger BP (middle), and pulse rate (bottom) during a 25 second Mueller manoeuvre of $-40 \mathrm{~cm} \mathrm{H}_{2} \mathrm{O}$ (subject 5). Note that the mouthpiece pressure scale is reversed.

manoeuvre (M2A) at $-20 \mathrm{~cm} \mathrm{H}_{2} \mathrm{O}$, but did not differ significantly at $-40 \mathrm{~cm} \mathrm{H}_{2} \mathrm{O}$. Investigating the effects of the two pressure levels of the manoeuvre, there was a trend towards greater reductions in IOP with lower mouthpiece pressures for both early and late manoeuvres. (M2A: $-2.8 \% \mathrm{v}$ M4A: $-13.8 \%$ and M2B: $-9.2 \% v$ M4B: $-15.6 \%$ respectively). However, this difference reached significance for early manoeuvres only $(\mathrm{p}<0.01)$. The effects of timing of measurements and of levels of negative pressures are graphically shown in Figure 4. The pressure-IOP response relation was further explored by linear regression analysis over the whole range of generated mouth pressures and IOP responses (Fig 6). There was a significant correlation between the change in mouth pressure and the change in IOP $(\mathrm{p}=0.045)$ with a rate of decline corresponding to $4.9 \%$ per $10 \mathrm{~cm} \mathrm{H}_{2} \mathrm{O}$ decrease in mouthpiece pressure.

Negative mouthpiece pressure produced marked intraindividual and interindividual variations in magnitude and direction of change in POBF (Table 3). Inspection of OBF generated printouts revealed slightly distorted IOP pulse waves during the Mueller manoeuvre in some of the participants, in particular subjects 5 and 7 during the first set of manoeuvres (that is, M2A and M2B). When irregular pulse waves were selected by the OBF tonograph, in general they were associated with both high pulse rates and high POBF values.

Overall, because of the variability of the results, negative mouthpiece pressure was only weakly associated with an increase in POBF. Whereas many subjects showed a significant increase in POBF, in particular for the measurements M2B and M4B, this was not the case for others (for example, subjects $1,5,6)$. As a result, the group average change in POBF reached significance for $-40 \mathrm{~cm} \mathrm{H}_{2} \mathrm{O}$ only $(\mathrm{p}=0.039)$. Figure 5 displays the average effect of the two manoeuvres on POBF.

Table 1 Demographic data and pooled baseline measurements of BP, IOP, and POBF

\begin{tabular}{|c|c|c|c|c|c|c|}
\hline \multirow[b]{2}{*}{ Subject } & \multirow[b]{2}{*}{ Sex } & \multirow[b]{2}{*}{ Eye } & \multirow[b]{2}{*}{ Age (years) } & \multirow{2}{*}{$\frac{\text { Brachial BP }}{\text { SBP/DBP }(\mathrm{mm} \mathrm{Hg})}$} & \multirow[b]{2}{*}{ Baseline IOP* (mm Hg) } & \multirow[b]{2}{*}{ Baseline POBF* $(\mu \mathrm{l} / \mathrm{min})$} \\
\hline & & & & & & \\
\hline 1 & $\mathrm{~F}$ & $\mathrm{R}$ & 28 & $101.7 / 65.7$ & 19.6 & 664.2 \\
\hline 2 & $\mathrm{~F}$ & $\mathrm{~L}$ & 25 & $101.0 / 62.3$ & 23.7 & 506.7 \\
\hline 3 & $\mathrm{~F}$ & $\mathrm{~L}$ & 40 & $105.7 / 68.3$ & 18.1 & 645.8 \\
\hline 4 & $M$ & L & 24 & $112.0 / 64.0$ & 18.6 & 584.5 \\
\hline 5 & $M$ & $\mathrm{~L}$ & 35 & $103.3 / 62.0$ & 10.6 & 589.4 \\
\hline 6 & $M$ & L & 29 & $114.7 / 64.0$ & 15.5 & 536.4 \\
\hline 7 & $M$ & $\mathrm{R}$ & 34 & $112.7 / 70.0$ & 16.9 & 523.7 \\
\hline All & & & 30.7 & $107.3 / 65.2$ & 17.6 & 578.7 \\
\hline
\end{tabular}

${ }^{*}$ Average of $B 1$ and $B 2$. 
Table 2 The effect of Mueller manoeuvres $\left(-20 \mathrm{~cm} \mathrm{H}_{2} \mathrm{O}\right.$ and $-40 \mathrm{~cm} \mathrm{H}_{2} \mathrm{O}$ ) on IOP relative to baseline measurements

\begin{tabular}{|c|c|c|c|c|c|c|c|c|c|c|}
\hline \multirow[b]{3}{*}{ Subject } & \multicolumn{5}{|c|}{ Mueller manoeuvre $-20 \mathrm{~cm} \mathrm{H}_{2} \mathrm{O}$} & \multicolumn{5}{|c|}{ Mueller manoeuvre $-40 \mathrm{~cm} \mathrm{H}_{2} \mathrm{O}$} \\
\hline & \multicolumn{2}{|c|}{ Inspiratory effort } & \multicolumn{3}{|c|}{ Change in IOP relative to baseline } & \multicolumn{2}{|c|}{ Inspiratory effort } & \multicolumn{3}{|c|}{ Change in IOP relative to baseline } \\
\hline & $\begin{array}{l}\text { Duration } \\
\text { (seconds) }\end{array}$ & $\begin{array}{l}\text { Mean P } \\
\left(\mathrm{cm} \mathrm{H} \mathrm{H}_{2} \mathrm{O}\right)\end{array}$ & $\begin{array}{l}\mathrm{M} 2 \mathrm{~A} \\
(\% \text { (SD)) }\end{array}$ & $\begin{array}{l}\text { M2B } \\
(\%(S D))\end{array}$ & $p$ value & $\begin{array}{l}\text { Duration } \\
\text { (seconds) }\end{array}$ & 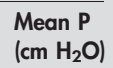 & $\begin{array}{l}\text { M4A } \\
(\% \text { (SD)) }\end{array}$ & $\begin{array}{l}\text { M4B } \\
(\% \text { (SD)) }\end{array}$ & p value \\
\hline 1 & 28.4 & -25.4 & $-10.6(5.7) \dagger$ & $-22.6(5.7) \pm \S$ & $<0.001$ & 27.4 & -45.8 & $-17.7(7.8) \dagger$ & $-24.7(8.3) \ddagger$ & 0.001 \\
\hline 2 & 14.6 & -15.0 & $4.0(0.9) \dagger$ & $0.4(2.4) \S$ & 0.010 & 29.8 & -38.1 & $-18.7(4.5) \ddagger$ & $-13.6(2.7) \ddagger \S$ & $<0.001$ \\
\hline 3 & 15.0 & -15.8 & $-2.2(8.2)$ & $-0.9(3.7)$ & & 22.9 & -34.8 & $-12.2(0.8) \ddagger$ & $-7.1(5.5) \dagger \S$ & 0.001 \\
\hline 4 & 15.8 & -15.3 & $6.4(2.7) \ddagger$ & $-3.2(3.1) \S$ & 0.001 & 31.0 & -44.7 & $-5.9(1.2) \dagger$ & $-4.3(1.2) \neq$ & $<0.001$ \\
\hline 5 & 41.9 & -21.6 & $-11.4(4.3) \dagger$ & $-13.7(4.4) \dagger$ & 0.002 & 21.4 & -37.3 & $-33.0(2.4) \ddagger$ & $-20.2(1.3) \mp \S$ & $<0.001$ \\
\hline 6 & 32.4 & -20.5 & $1.1(3.3)$ & $-12.1(2.3) \pm \S$ & $<0.001$ & 25.1 & -41.7 & $1.4(2.3)$ & $-9.5(3.8)+\S$ & 0.002 \\
\hline 7 & 42.7 & -22.6 & $-7.1(2.5) \dagger$ & $-12.2(3.6)+\S$ & 0.001 & 44.0 & -41.5 & $-10.8(3.5) \neq$ & $-29.5(2.6) \pm \S$ & $<0.001$ \\
\hline All & 27.3 & -19.5 & $-2.8(2.7)^{*}$ & $-9.2(3.1)^{*}+\S$ & 0.013 & 27.4 & -40.6 & $-13.8(4.1)^{*}+$ & $-15.6(3.6)^{*} \dagger$ & 0.004 \\
\hline
\end{tabular}

Analyses include repeated ANOVA and Student-Newman Keuls post hoc tests for each subject separately, and for the group as a whole. Only significant p values are shown.

${ }^{*}$ Group mean (SEM).

$t p \leqslant 0.05$ relative to baseline.

$\neq p \leqslant 0.01$ relative to baseline.

$\S p \leqslant 0.05$ relative to early Mueller manoeuvre.

Inspiratory effort varied both in duration and in created pressure among the subjects (Tables 2 and 3). Mean inspiratory pressures deviated slightly from the two target pressures (range: $0.5-5.8 \mathrm{~cm} \mathrm{H}_{2} \mathrm{O}$ difference), and most subjects (five out of seven) overshot or undershot in the same direction during both Mueller manoeuvres. In general, duration of the manoeuvres exceeded the minimum time of 15 seconds. Subjects 2, 3, and 4 completed the first manoeuvre within 1 second of the minimum time, whereas in all other cases duration of the manoeuvres exceeded the minimum time by between 6.4 and 27.7 seconds. On average, female subjects undershot pressure by $-0.9 \mathrm{~cm} \mathrm{H}_{2} \mathrm{O}$ and exceeded the minimum manoeuvre time by 8.0 seconds, whereas male subjects overshot pressure by $0.6 \mathrm{~cm} \mathrm{H}_{2} \mathrm{O}$ and exceeded the minimum manoeuvre time by 16.8 seconds. However, because of the small sample size neither pressure nor duration was significantly different between the sexes.

\section{DISCUSSION}

In this study we have demonstrated a significant association between inspiratory effort, as measured by negative mouth pressures, and an acute decline in IOP. In addition, by recording the change in IOP at two different levels of inspiratory effort we were able to show that a dose-response relation exists between the inspiratory effort and the magnitude of change in IOP. To the best of our knowledge this is the first time the effect of graded negative respiratory effort on IOP has been reported. However, the results are not surprising if we consider the intraocular fluid dynamics of the Valsalva manoeuvre. Several studies have shown that IOP may increase by up to $56 \%$ during the straining phase of the Valsalva manoeuvre-that is, phase II of the manoeuvre when the subject is maintaining a predetermined pressure (usually $40 \mathrm{~mm} \mathrm{Hg}$ ). ${ }^{34}{ }^{45-47}$ Most of this response is believed to be attributed to a mechanical effect of elevated intrathoracic pressure during the manoeuvre on venous return from the head, transmitted to the ocular venous pressure, ${ }^{48}$ and finally to the IOP by vascular volume changes within the rigid scleral chamber. ${ }^{49} 50$ In the corresponding phase of the Mueller manoeuvre - that is, when the subject is maintaining a constant negative pressure, the venous return to the heart is known to increase. ${ }^{51}$ As the venous return from the head is likely to increase by the same mechanism, associated reduction in episcleral venous pressure will lower outflow resistance leading to a drop in IOP through the same pressure-volume relation that accounts for the increase in IOP during the Valsalva manoeuvre. The suggested mechanism is supported by a significant positive linear relation that

Table 3 Effect of Mueller manoeuvres (-20 $\mathrm{cm} \mathrm{H}_{2} \mathrm{O}$ and $-40 \mathrm{~cm} \mathrm{H} \mathrm{H}_{2} \mathrm{O}$ ) on POBF relative to baseline measurements

\begin{tabular}{|c|c|c|c|c|c|c|c|c|c|c|}
\hline \multirow[b]{3}{*}{ Subject } & \multicolumn{5}{|c|}{ Mueller manoeuvre $-20 \mathrm{~cm} \mathrm{H}$} & \multicolumn{5}{|c|}{ Mueller manoeuvre $-40 \mathrm{~cm} \mathrm{H} \mathrm{H}_{2} \mathrm{O}$} \\
\hline & \multicolumn{2}{|c|}{ Inspiratory effort } & \multicolumn{3}{|c|}{ Change in POBF relative to baseline } & \multicolumn{2}{|c|}{ Inspiratory effort } & \multicolumn{3}{|c|}{ Change in POBF relative to baseline } \\
\hline & $\begin{array}{l}\text { Duration } \\
\text { (seconds) }\end{array}$ & $\begin{array}{l}\text { Mean } \mathrm{P} \\
\left(\mathrm{cm} \mathrm{H} \mathrm{H}_{2} \mathrm{O}\right)\end{array}$ & $\begin{array}{l}\text { M2A } \\
(\% \text { (SD)) }\end{array}$ & $\begin{array}{l}\text { M2B } \\
(\% \text { (SD)) }\end{array}$ & p value & $\begin{array}{l}\text { Duration } \\
\text { (seconds) }\end{array}$ & 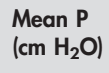 & $\begin{array}{l}\text { M4A } \\
(\% \text { (SD)) }\end{array}$ & $\begin{array}{l}\text { M4B } \\
(\% \text { (SD)) }\end{array}$ & p value \\
\hline 1 & 28.4 & -25.4 & $-14.7(13.5)$ & $-10.1(7.7)$ & & 27.4 & -45.8 & $7.8(18.1)$ & $19.7(11.3)$ & \\
\hline 2 & 14.6 & -15.0 & $17.6(10.4) \dagger$ & $13.0(18.7)$ & 0.045 & 29.8 & -38.1 & $31.4(6.2) \ddagger$ & $49.4(7.5) \pm \S$ & $<0.001$ \\
\hline 3 & 15.0 & -15.8 & $12.0(8.2) \dagger$ & $14.2(13.0) \dagger$ & 0.008 & 22.9 & -34.8 & 28.9 (8.4)‡ & $26.4(7.6) \ddagger$ & $<0.001$ \\
\hline 4 & 15.8 & -15.3 & $20.2(10.2) \ddagger$ & $12.2(10.9) \dagger \S$ & $<0.001$ & 31.0 & -44.7 & $29.8(5.1) \ddagger$ & $20.4(8.2) \pm \S$ & $<0.001$ \\
\hline 5 & 41.9 & -21.6 & $7.4(15.9)$ & $32.8(69.8)$ & & 21.4 & -37.3 & $-15.5(8.2) \ddagger$ & $-8.1(8.5) \S$ & $<0.001$ \\
\hline 6 & 32.4 & -20.5 & $-0.7(6.1)$ & $5.6(11.3)$ & & 25.1 & -41.7 & $-15.2(6.4) \ddagger$ & 11.1 (9.9)§ & $<0.001$ \\
\hline 7 & 42.7 & -22.6 & $45.2(36.5) \dagger$ & $79.2(42.5) \dagger$ & 0.014 & 44.0 & -41.5 & $-6.7(9.5)$ & $17.6(15.2) \S$ & 0.028 \\
\hline All & 27.3 & -19.5 & $12.4(7.1)^{*}$ & $21.0(10.8)^{*}$ & & 27.4 & -40.6 & $8.6(8.1)^{*}$ & $19.5(6.5)^{*} \dagger$ & 0.039 \\
\hline
\end{tabular}

Analyses include repeated ANOVA and Student-Newman Keuls post hoc tests for each subject separately, and for the group as a whole. Only significant $p$ values are shown.

${ }^{*}$ Group mean (SEM).

$\mathrm{tp} \leqslant 0.05$ relative to baseline.

$\neq \mathrm{p} \leqslant 0.01$ relative to baseline.

$\S p \leqslant 0.05$ relative to early Mueller manoeuvre. 


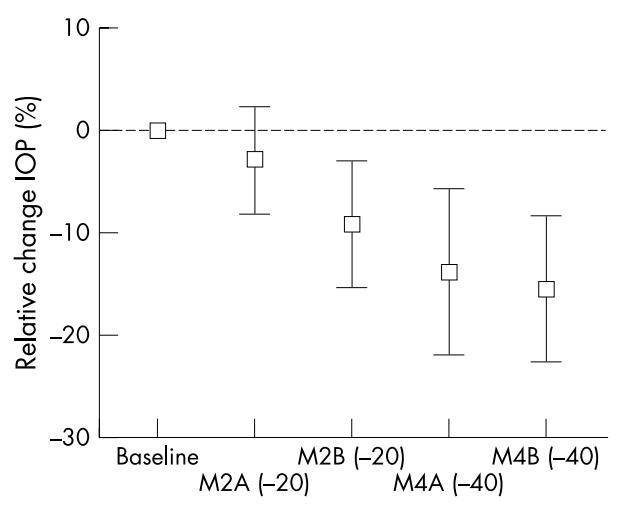

Figure 4 Relative change (\%) in intraocular pressure (IOP) for the total sample of subjects $(n=7)$. Data are presented as means (SEM). M2A and M4A represent measurements 5-10 seconds into the Mueller manoeuvres $\left(-20 \mathrm{~cm} \mathrm{H}_{2} \mathrm{O}\right.$ and $-40 \mathrm{~cm} \mathrm{H}_{2} \mathrm{O}$, respectively), and $\mathrm{M} 2 \mathrm{~B}$ and $\mathrm{M} 4 \mathrm{~B}$ represent measurements directly after the manoeuvres $\left(-20 \mathrm{~cm} \mathrm{H} \mathrm{H}_{2} \mathrm{O}\right.$ and $-40 \mathrm{~cm} \mathrm{H}_{2} \mathrm{O}$, respectively).

was found for the dependence of the decrease in IOP upon the negative mouth pressure in the approximate range from $-20 \mathrm{~cm} \mathrm{H}_{2} \mathrm{O}$ to $-40 \mathrm{~cm} \mathrm{H}_{2} \mathrm{O} \quad(\mathrm{p}=0.045)$. In this doseresponse relationship the estimated rate of decline in IOP was found to be $4.9 \%$ per $10 \mathrm{~cm} \mathrm{H}_{2} \mathrm{O}$ of negative intrathoracic pressure. There are no reports available by which this rate can be compared with the effects of positive intrathoracic pressures; however, the existence of a similar dose-response has been reported with graded Valsalva manoeuvres and graded Valsalva-like expiratory efforts. ${ }^{45} 52$

The mean duration of the two manoeuvres were nearly the same (27.3 and 27.4 seconds respectively), but the difference between early and late measurements reached significance for the lower negative pressure only ( M2A $v \mathrm{M} 2 \mathrm{~B}, \mathrm{p}<0.05$ ). This indicates that the effect of negative intrathoracic pressures on IOP rapidly reaches its maximum at higher levels of inspiratory efforts whereas at low levels the decline in IOP is less steep.

Pulsatile ocular blood flow measurements were characterised by marked intraindividual and interindividual variability (Table 3). Most likely this can be explained by the effect of the manoeuvre on variables that form the POBF-that is, ocular pulse wave and heart rate. The cardiovascular effects of the Mueller manoeuvre are well described. ${ }^{37}$ Negative

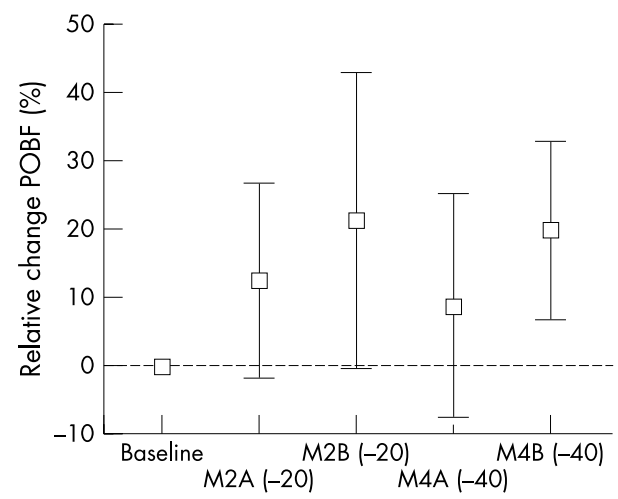

Figure 5 Relative change (\%) in pulsatile ocular blood flow for the total sample of subjects $(n=7)$. Data are presented as means (SEM). M2A and M4A represent measurements 5-10 seconds into the Mueller manoeuvres $\left(-20 \mathrm{~cm}{ }_{2} \mathrm{O}\right.$ and $-40 \mathrm{~cm} \mathrm{H}_{2} \mathrm{O}$, respectively), and $\mathrm{M} 2 \mathrm{~B}$ and $\mathrm{M} 4 \mathrm{~B}$ represent measurements directly after the manoeuvres $\left(-20 \mathrm{~cm} \mathrm{H}_{2} \mathrm{O}\right.$ and $-40 \mathrm{~cm} \mathrm{H}_{2} \mathrm{O}$, respectively).

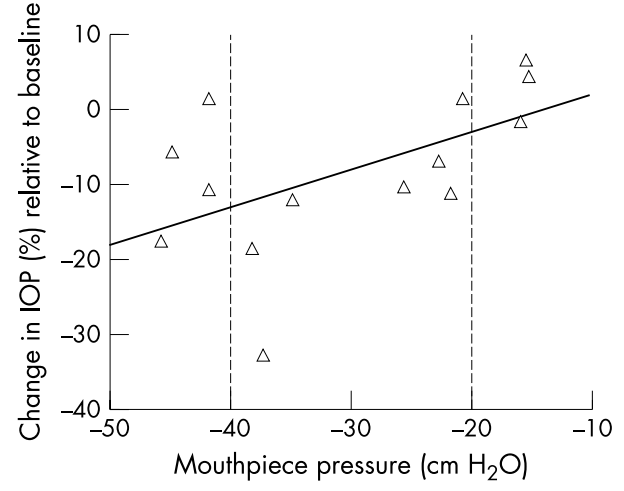

Figure 6 Linear regression analysis between the relative change in IOP and the absolute change in mouthpiece pressure generated during the manoeuvres (that is, M2A and M4A) $(n=14)$. Vertical reference lines mark the aimed pressure levels of the two Mueller manoeuvres. $r^{2}=0.29(p=0.045)$.

pleural pressure swings of the manoeuvre are associated with fluctuations in both cardiac stroke volume and heart rate, which in turn will influence the outcome of the mathematically derived POBF. ${ }^{53}$ As these cardiovascular responses have been shown to vary considerably between subjects performing the manoeuvre, ${ }^{55} 56$ we could expect greater variability in POBF measurements than during normal breathing. Group averages of POBF, nevertheless, demonstrated a clear trend towards manoeuvre induced increments (Fig 5), and in spite of the small sample size this effect was significant for late measurements at pressures of $-40 \mathrm{~cm} \mathrm{H}_{2} \mathrm{O} \quad(\mathrm{p}=0.039)$. These results are directionally opposite to the effect of the Valsalva manoeuvre on POBF as reported by Schmetterer et al. ${ }^{34}$ In their study OBF measurements at the end of Valsalva manoeuvres of $40 \mathrm{~mm} \mathrm{Hg}$ (corresponding to $53.3 \mathrm{~cm} \mathrm{H}_{2} \mathrm{O}$ ) produced a reduction in POBF of $7 \%$, which was less than the increase of 8.6-19.5\% found during the graded Mueller manoeuvres in our study. However, although the respiratory stimuli in both studies were approximately of the same strength and duration, results should be compared with caution for several reasons. Firstly, measurements in the two studies were obtained at different phases of the employed manoeuvres. This means that the recorded vascular response reflects not only the mechanical effect of positive or negative intrathoracic pressures on the cardiovascular system, but also baroreceptor and chemoreceptor activity in response to changes in arterial pressure and blood gases at the time of the measurement. ${ }^{385758}$ It is, therefore, possible that the magnitude of response found in our late measurements can be explained, at least partly, by the fact that these were obtained during the recovery phase of the Mueller manoeuvre when the release of inspiratory strain and a concomitant increase in sympathetic outflow are known to cause marked increases in blood pressure, pulse pressure and heart rate. ${ }^{58}$ Secondly, while measurements were obtained in a supine position during the Mueller manoeuvre, subjects were sitting in the study of Schmetterer et al. ${ }^{34}$ Recent studies have found that posture influences the cardiovascular responses to the Valsalva and Mueller manoeuvres. ${ }^{55} 596$ The greater decrease in IOP when subjects performed the Valsalva manoeuvre in a supine versus sitting position indicates that this may also hold true for the ocular response. ${ }^{45}$ Hence, the magnitude of responses to the Valsalva and Mueller manoeuvres in both studies may have been closer if they had been performed with the same posture. 
There are a number of limitations in this study that need to be addressed. One of the major problems is that manoeuvres were not randomly ordered. Although IOP measurements with the OBF have shown acceptable accuracy ${ }^{33} 35$ and testretest reproducibility, ${ }^{31}{ }^{34}$ it is well established that repeated applanation tonometry can produce a reduction in IOP through a massaging effect of the eyeball. ${ }^{61}$ That this effect may hold true also for the OBF machine is indicated in a study by Kergoat and Faucher, ${ }^{62}$ where repeated measurements significantly reduced IOP, although did not significantly affect POBF measurements.

Another factor that may have affected our results is the negative relation that has been shown to exist between ocular axial length and POBF. ${ }^{63}$ The effect that this is expected to have on interindividual variability was compensated for by the experimental design whereby subjects served as their own controls. As the effect of a change in the volume of each blood bolus entering the eye will depend on the total volume of the eye, there are reasons to control for axial length in any studies where a stimulus will impose effects on the systemic circulation (for example, respiratory manoeuvres, $\mathrm{O}_{2}, \mathrm{CO}_{2}$ breathing).

Finally, there is a need to comment on the method that was used to measure ocular blood flow in this study. Although pneumotonography and the IOP waveform based calculation of pulsatile ocular blood flow has become a widely accepted technique through the availability of the Langham and OBF systems, the question remains unanswered as to what properties of ocular blood flow this technique truly measures. Calculation of the ocular pulse volume that forms the basis of the algorithmically derived POBF, is based on the assumption that the pressure-volume relation of the eye $\mathrm{e}^{5064}$ is constant. ${ }^{27} 28{ }^{65}$ However, experimental work on rabbits has shown that the pressure-volume relation is dependent on systemic arterial pressure because of its effect on blood volume and possibly because of myogenic autoregulatory properties of the choroid. ${ }^{66}{ }^{67}$ As pointed out by Kiel, ${ }^{67}$ this may entail a potential source of error when ocular blood flow is measured with the OBF system at different systemic blood pressures. Hence, this method may not be ideal for blood flow quantification during respiratory manoeuvres.

The study presented was inspired by an accumulating number of reports on the possible relation between obstructive sleep-apnoea and neuro-ophthlamological consequences. ${ }^{21-25} 68$ Because of the inaccessibility of the eye during sleep, we chose to study the acute consequences of obstructive apnoea by graded Mueller manoeuvres. Contrary to the reported haemodynamics of obstructive apnoea and the Mueller manoeuvre, ${ }^{37}{ }^{69}$ there was a significant decrease in IOP that lasted into the recovery period of the manoeuvre. These observations are in concordance with the stable IOP after prolonged apnoea events that Mojon and coworkers. ${ }^{70}$ reported in a case series of three patients with moderate sleep apnoea. Although lowering of IOP may promote perfusion of the ocular structures, as indicated by the increased POBF found in this study, we are not able to tell whether this holds true in an older population or in repeated obstructive sleep apnoea. As the apnoea is related to both acute fluctuations in systemic blood pressure, intracranial pressure and blood gases, and long term adaptations of the autonomic regulatory mechanisms, ${ }^{71}$ there are several mechanisms that may be involved in a possible link between this common sleep disorder and the reported ophthalmological findings. Further research in this field is therefore warranted.

\section{ACKNOWLEDGEMENTS}

P Lundmark received partial support from the Glaucoma Research Society of Canada. J Flanagan and G Trope are supported by the Canadian Institutes of Health Research.

\section{Authors' affiliations}

P O Lundmark, G E Trope, J G Flanagan, Department of Ophthalmology and Vision Sciences, Toronto Western Hospital, East Wing 6-503 399, Bathurst Street, Toronto, ON M5T 2S8, Canada

P O Lundmark, G E Trope, J G Flanagan, Glaucoma Research Unit, Toronto Western Hospital Research Institute, University Health Network, Toronto, Canada

P O Lundmark, Department of Optometry and Vision Sciences, Buskerud University College, Kongsberg, Norway

J G Flanagan, School of Optometry, University of Waterloo, Waterloo, Canada

\section{REFERENCES}

1 Duke-Elder S, Gloster J. The intra-ocular pressure. In: Duke-Elder S, ed. System of ophthalmology, Vol IV. London: Henry Kimpton, 1968:227-336.

2 Pickering T, ed. Ambulatory blood pressure. Spacelabs Medical, 1994:10-19.

3 Joyner MJ, Shepherd JT. Autonomic control of circulation. In: Low PA, ed. Clinical autonomic disorders. Boston, Toronto, London: Little, Brown, 1992:55-67.

4 Guilleminault C, Tilkian A, Dement WC. The sleep apnea syndromes. Annu Rev Med 1976;27:465-82.

5 Wilcox PG, Pare PD, Road JD, et al. Respiratory muscle function during obstructive apnea. Am Rev Respir Dis 1990;142:533-9.

6 Young T, Palta M, Dempsey J, et al. The occurrence of sleep-disordered breathing among middle-aged adults. N Engl J Med 1993;328:1230-5.

7 Garpestad E, Katayama H, Parker JA, et al. Stroke volume and cardiac output decrease at termination of obstructive apneas. J Appl Physiol 1992:73:1743-8

8 Shepard JW Jr. Cardiopulmonary consequences of obstructive sleep apnea. Mayo Clin Proc 1990;65:1250-9.

9 Stoohs R, Guilleminault C. Cardiovascular changes associated with obstructive sleep apnea syndrome. J Appl Physiol 1992;72:583-9.

10 Jennum P, Börgensen SE. Intracranial pressure and obstructive sleep apnea. Chest 1989;95:279-83.

11 Bålfors EM, Franklin KA. Impairment of cerebral perfusion during obstructive sleep apneas. Am J Respir Crit Care Med 1994;150:1587-91.

12 Diomedi M, Placidi F, Cupini LM, et al. Cerebral hemodynamic changes in sleep apnea syndrome and effect of continuous positive airway pressure treatment. Neurology 1998;51:1051-6.

13 Sugita $Y$, Lijima S, Teshima $Y$, et al. Marked episodic elevation of cerebrospinal fluid during nocturnal sleep in patients with sleep apnea hypersomnia syndrome. Electroenceph Clin Neurophysiol 1985;60:214-19.

14 Partinen M, Jamieson A, Guilleminault C. Long term outcome for obstructive sleep apnea syndrome patients: mortality. Chest 1988;94:1200-4.

15 Hung J. Association of sleep apnoea with myocardial infarction in men. Lancet 1990;336:261-4.

16 Noda A, Okada T, Yasuma F, et al. Cardiac hypertrophy in obstructive sleep apnea syndrome. Chest 1995; 107:1538-44.

17 Palomäki H, Partinen M, Erkinjuntti T, et al. Snoring, sleep anpea syndrome, and stroke. Neurology 1992;42:S75-82.

18 Palomäki H, Partinen M, Juvela $S$, et al. Snoring as a risk factor for sleep related brain infarction. Stroke 1989;20:1311-15.

19 Lugaresi E, Cirignotta F, Coccagna G. Some epidemiological data on snoring and cardiocirculatory disturbances. Sleep 1980;3:221-4.

20 Dyken ME, Somers VK, Yamada T, et al. Investigating the relationship between stroke and obstructive sleep apnea. Stroke 1996;27:401-7.

21 Mojon DS, Hess CW, Goldblum D, et al. High prevalence of glaucoma in patients with sleep apnea syndrome. Ophthalmology 1999;106:1009-12.

22 Hayreh SS. Acute ischemic disorders of the optic nerve: pathogenesis, clinical manifestations and management. Ophthalmol Clin North Am 1996;9:407-42.

23 Mojon DS, Mathis J, Zulauf M, et al. Optic neuropathy associated with sleep apnea syndrome. Ophthalmology 1998;105:874-7.

24 Purvin VA, Kawasaki A, Yee RD. Papilledema and obstructive sleep apnea syndrome. Arch Ophthalmol 2000;118:1626-30.

25 Bucci FA Jr, Krohel GB. Optic nerve swelling secondary to the obstructive sleep apnea syndrome. Am J Ophthalmol 1988;105:428-9.

26 Langham ME, Farrell RA, O'Brien V, et al. Non-invasive measurement of pulsatile blood flow in the human eye. In: Lambrou GN, Greve EL, ed. Ocular blood flow in glaucoma Kugler \& Ghedini, 1989:93-9.

27 Langham ME, Farrell RA, O'Brien V, et al. Blood flow in the human eye. Acta Ophthalmol 1989:67:9-13.

28 Silver DM, Farrell RA, Langham ME, et al. Estimation of pulsatile ocular blood flow from intraocular pressure. Acta Ophthalmol 1989;67:25-9.

29 Alm A. Ocular circulation. In: Hart WM, ed. Adler's physiology of the eye. 9th ed. St Louis: CV Mosby, 1992:198-227.

30 Krakau CE. A model for pulsatile and steady ocular flow. Graefes Arch Clin Exp Ophthalmol 1995;233:112-18.

31 Yang YC, Hulbert MFG, Batterbury M, et al. Pulsatile ocular blood flow measurements in healthy eyes: Reproducibility and reference values. J Glaucoma 1997:6:175-9.

32 Butt Z, O'Brien C. Reproducibility of pulsatile ocular blood flow measurements. J Glaucoma 1995;4:214-18.

33 Bafa M, Lambrinakis I, Dayan M, et al. Clinical comparison of the measurement of the IOP with the ocular blood flow tonometer, the Tonopen XL 
and the Goldmann applanation tonometer. Acta Ophthalmol Scand 2001;79:15-18.

34 Schmetterer L, Dallinger S, Findl O, et al. Noninvasive investigations of the normal ocular circulation in humans. Invest Ophthalmol Vis Sci 1998:39:1210-20.

35 Spraul CW, Lang GE, Ronzani M, et al. Reproducibility of measurements with a new slit lamp-mounted ocular blood flow tonograph. Graefes Arch Clin Exp Ophthalmol 1998;236:274-9.

36 Miyazaki M. Circulatory effect of respiratory maneuvers. Angiology 1978:29:541-7.

37 Scharf SM. Cardiovascular effects of airways obstruction. Lung 1991;169:1-23.

38 Somers VK, Dyken ME, Skinner JL. Autonomic and hemodynamic responses and interactions during the Mueller maneuver in humans. J Autonom Nerv Syst 1993;44:253-4.

39 Hanley PJ, George CF, Millar TW, et al. Heart rate response to breath-hold, Valsalva and Mueller maneuvers in obstructive sleep apnea. Chest 1989:95:735-9.

40 Hall MJ, Ando S, Floras JS, et al. Magnitude and time course of hemodynamic responses to Mueller maneuvers in patients with congestive heart failure. $J$ Appl Physiol 1998;85:1476-84.

41 Permutt S, Wise RA, Brower RG. How changes in pleural and alveolar pressure cause changes in afterloads and preloads. In Scharf SM, Cassidy SS, ed. Heart-lung interactions in health and disease. New York: Marcel Decker, 1989:243-50.

42 Krieger J, Sforza E, Bovewijns A, et al. Respiratory effort during obstructive sleep apnea: role of age and sleep state. Chest 1997:112:875-9.

43 Garpestad E, Ringler J, Parker JA, et al. Sleep stage influences the hemodynamic response to obstructive apneas. J Appl Physiol 1995; 74:1123-30

44 Ringler J, Basner RC, Shanon R, et al. Hypoxemia alone does not explain blood pressure elevations after obstructive apneas. J Appl Physiol 1990:69:2143-8.

45 Oggel K, Sommer G, Neuhann Th, et al. Verandrungen des Augesinnendruckes bei intrathorokaler Druckerhohung in Abhangigkeit von der Korperposition und der Achsenlange des Augapfels. Graefes Arch Clin Exp Ophthalmol 1982;218:51-4.

46 Lanigan LP, Clark CV, Allawin J, et al. Intraocular pressure responses to systemic autonomic stimulation in diabetes mellitus. Doc Ophthalmol 1989;72:141-53

47 Lanigan LP, Clark CV, Hill DW. Intraocuar pressure responses to systemic autonomic stimulation. Eye 1989:3:477-83.

48 Macri FJ. Acetazolamide and the venous pressure of the eye. Arch Ophthalmol 1960;63:953-65.

49 Friedenwald JS. Contribution to the theory and practice of tonometry. Am J Ophthalmol 1937:20:985-1024.

50 Eisenlohr JE, Langham ME, Maumenee AE. Manometric studies of the pressure volume relationships in living and enucleated eyes of individual human subjects. Br J Ophthalmol 1962;46:536-48.

51 Magder SA, Lichtenstein S, Adelman AG. Effects of negative pleural pressure on left ventricular hemodynamics. Am J Cardiol 1983;52:588-93.
52 Schuman JS, Craig Massicotte E, Connolly S, et al. Increased intraocular pressure and visual field defects in high resistance wind instrument players. Ophthalmology 2000;107:127-33.

53 Trew DR. Factors influencing the ocular pulse-the heart rate. Graefes Arch Clin Exp Ophthalmol 1991:229:553-6.

54 Bosley TM, Cohen MS, Gee W, et al. Amplitude of the ocular pneumoplethysmography waveform is correlated with cardiac output. Stroke 1993;24:6-9.

55 Scharf S, Tow DE, Miller MJ, et al. Influence of posture and abdominal pressure on the hemodynamic effects of Mueller's maneuver. J Crit Care 1989;4:26-34.

56 Scharf SM, Brown R, Tow DE, et al. Cardiac effects of increased lung volume and decreased pleural pressure in man. J Appl Physiol 1979;47: $257-62$.

57 Sandroni P, Benarroch EE, Low PA. Pharmacological dissection of components of the Valsalva maneuver in adrenergic failure. J Appl Physiol 1991;71:1563-7.

58 Morgan BJ, Denahan T, Ebert TJ. Neurocirculatory consequences of negative intrathoracic pressure vs. asphyxia during voluntary apnea. J Appl Physiol 1993;74:2969-75.

59 Goldish GD, Quast JE, Blow JJ, et al. Postural effects on intra-abdominal pressure during Valsalva maneuver. Arch Phys Med Rehabil 1994;75: $324-7$.

60 Singer W, Opfer-Gehrking TL, McPhee BR, et al. Influence of posture on the Valsalva manoeuvre. Clin Sci 2001;100:433-40.

61 Whitacre MM, Stein R. Sources of error with use of Goldmann-type tonometers. Surv Ophthalmol 1993;38: 1-30.

62 Kergoat $\mathrm{H}$, Faucher $\mathrm{C}$. Effects of oxygen and carbogen breathing on choroidal hemodynamics in humans. Invest Ophthalmol Vis Sci 1999;40:2906-11.

63 James CB, Trew DR, Clark K, et al. Factors influencing the ocular pulse-axial length. Graefes Arch Clin Exp Ophthalmol 1991;229:341-4.

64 Ytteborg J. The rate of intraocular blood volume in rigitity measurements on human eyes. Acta Ophthalmol (Kbh) 1960;38:410-36.

65 Krakau CET. Calculation of the pulsatile ocular blood flow. Invest Ophthalmol Vis Sci 1992;33:2754-6.

66 Kiel JW. Choroidal myogenic autoregulation and intraocular pressure. Exp Eye Res 1994;58:529-44.

67 Kiel JW. The effect of arterial pressure on the ocular pressure-volume relationship in the rabbit. Exp Eye Res 1995;60:267-78

68 Marcus DM, Lynn J, Miller JJ, et al. Sleep disorders: a risk factor for pseudotumor cerebri? J Neuro-Ophthalmol 2001:21:121-3.

69 Robinson A, Guilleminault C. Obstructive sleep apnea syndrome. In: Shokroverty S, ed. Sleep disorders medicine: basic science, technical considerations, and clinical aspects, 2nd ed. Oxford: Butterworth-Heinemann, 1999:331-54

70 Goldblum D, Mathis J, Bohnke M, et al. Nachtliche Messungen des Intraokulardrucks bei Patienten mit Normaldruckglaukom und Schlaf-ApnoeSyndrom. Klin Monatsbl Augenheilkd 2000;216:246-9.

71 Smith RP, Veale D, Pepin J-L, et al. Obstructive sleep apnoea and the autonomic nervous system. Sleep Med Rev 1998;2:69-92. 